\title{
Decoupling the Relation Between Risk Factors for Conduct Problems and the Receipt of Intervention Services: Participation Across Multiple Components of a Prevention Program
}

\author{
Robert L. Nix ${ }^{1,5}$, Ellen E. Pinderhughes ${ }^{2}$, Karen L. Bierman ${ }^{1}$, Jerry J. Maples ${ }^{3}$, and The \\ Conduct Problems Prevention Research Group ${ }^{4}$ \\ ${ }^{1}$ Pennsylvania State University. \\ ${ }^{2}$ Tufts University. \\ ${ }^{3}$ United States Census Bureau.
}

\begin{abstract}
This study examined whether the link between risk factors for conduct problems and low rates of participation in mental health treatment could be decoupled through the provision of integrated prevention services in multiple easily-accessible contexts. It included 445 families of first-grade children (55\% minority), living in four diverse communities, and selected for early signs of conduct problems. Results indicated that, under the right circumstances, these children and families could be enticed to participate at high rates in school-based services, therapeutic groups, and home visits. Because different sets of risk factors were related to different profiles of participation across the components of the prevention program, findings highlight the need to offer services in multiple contexts to reach all children and families who might benefit from them.
\end{abstract}

\section{Keywords}

participation; prevention; treatment; behavior problems

Often, those children and families who experience the most severe problems are least likely to receive the treatment they need. This study examined whether that trend could be averted through an indicated prevention program that offered intervention services in multiple contexts within the community, including children's schools and families' homes.

Serious and persistent conduct problems present an important public health issue. With a prevalence rate above 5\% (Offord et al., 1987), such problems comprise the most common class of psychiatric disorders in children and account for a majority of children's referrals to mental health services (Robins, 1981). Many children with conduct problems, however, receive little or no mental health treatment in any setting (Leaf et al., 1996; Wu et al., 1999).

Even when mental health treatment is available, motivating participation and warding off premature termination can be a challenge. Estimates from meta-analyses suggest that $47 \%$ of

(C) 2005 Springer Science+Business Media, Inc.

5To whom correspondence should be addressed at Robert Nix, Prevention Research Center, 109 South Henderson Building, Pennsylvania State University, University Park, PA 16802; rnix@ psu.edu..

${ }^{4}$ Ellen Pinderhughes's and Karen Bierman's colleagues in the Conduct Problems Prevention Research Group are, in alphabetical order, John D. Coie, Duke University; Kenneth A. Dodge, Duke University; E. Michael Foster, University of North Carolina; Mark T. Greenberg,

Pennsylvania State University; John E. Lochman, University of Alabama; and Robert J. McMahon, University of Washington. 
children drop out of psychological treatment (Wierzbicki \& Pekarik, 1993), and 28\% of parents drop out of behavior management classes (Forehand, Middlebrook, Rogers, \& Steffe, 1983).

\section{Risk Factors for Conduct Problems and Low Rates of Participation in Treatment}

This problem of inducing participation is central to the success of mental health services because the same risk factors that increase the likelihood of children's conduct problems also predict low rates of participation in treatment. In fact, the children and families who stop treatment early may experience $50 \%$ more risk factors than children and families who complete treatment (Kazdin, Mazurick, \& Bass, 1993).

\section{Family Demographics}

Many family demographic characteristics are risk factors for children's conduct problems and for children's and families' low rates of participation in treatment. For example, low rates of maternal education and family poverty are related to high levels of child antisocial behavior (Nagin \& Tremblay, 2002; McLeod \& Shanahan, 1996). African American children have higher prevalence rates of conduct problems, but this race difference often disappears once family socioeconomic status (SES) is taken into account (McDermott \& Spencer, 1997). When families are characterized by marital discord and multiple changes in composition, children are more likely to display conduct problems (Ackerman, Brown, D'Eramo, \& Izard, 2002; Tiet et al., 2001). In addition, the children of adolescent mothers are at increased risk for displaying conduct problems (Jaffee, Caspi, Moffitt, Belsky, \& Silva, 2001).

Empirical research has demonstrated relations between those same family demographic characteristics and low rates of participation in intervention programs targeting children's conduct problems. For example, mothers who are relatively poor, less educated, and young are less likely to attend and complete behavior management classes (Firestone \& Witt, 1982; Rinn, Vernon, \& Wise, 1975). African American and Latino parents are less likely to complete the extended evaluations of children's problems that are usually a prerequisite to treatment (Armbruster \& Schwab-Stone, 1994). Although single mothers are more likely to bring their children to treatment than married mothers (Wierzbicki \& Pekarik, 1993), they appear less likely to attend treatment that involves their own participation (Clark \& Baker, 1983).

\section{Adult Psychological Functioning}

Many aspects of adult psychological functioning are related to both the prevalence of children's conduct problems and low rates of participation in traditional mental health services. Parents with antisocial characteristics, substance abuse problems, or depression are more likely to have children with conduct problems (Lahey et al., 1995; Loeber, Green, Keenan, \& Lahey, 1995; Luoma et al., 2001). Experiencing multiple negative and stressful life events and few positive life events also is related to children's behavior problems, including elevated levels of aggression and referral to child guidance clinics (Myers, Taylor, Alvy, Arrington, \& Richardson, 1992; Stanger, McConaughy, \& Achenbach, 1992).

Those same aspects of adult psychological functioning are related to families' participation in treatment. Mothers with a history of antisocial behavior or symptoms of depression near the clinical range are less likely to attend parent training (Firestone \& Witt, 1982; Kazdin et al., 1993; McMahon, Forehand, Greist, \& Wells, 1981). In addition, parents with many stressful life events are more likely to prematurely terminate treatment for their children (Kazdin, 1990). 


\section{Parenting Practices}

Most likely, risk factors such as family income and mothers' depression increase the likelihood of children's conduct problems because they undermine attention to and motivation for appropriate care-giving (Wahler \& Dumas, 1989; Webster-Stratton, 1990). Over-reactive and harsh discipline predicts the development of externalizing behavior problems in young children, even after controlling for initial levels of problems (O'Leary, Slep, \& Reid, 1998). Parental verbal aggression also has been related to children's physical aggression, delinquency, and social problems (Vissing, Straus, Gelles, \& Harrop, 1991).

Mothers engaged in adverse childrearing practices, such as harsh and inconsistent discipline and poor supervision, are less likely to complete treatment than mothers with more positive parenting practices (Kazdin et al., 1993). Contentious parent-child relationships also predict early drop out from treatment (Kazdin, 1990). In addition, mothers who feel less competent about their own ability to function in the parenting role and who are less knowledgeable about behavior modification principles are at increased risk for dropping out of interventions early (Kazdin, 1990; Clark \& Baker, 1983).

\section{Child Characteristics}

Child characteristics also affect the likelihood of conduct problems and rates of participation in intervention programs. Physically aggressive behaviors and fighting portend some of the worst outcomes (Loeber et al., 1995; Nagin \& Tremblay, 1999); such behaviors, displayed early in life and in multiple contexts, almost always precede the most serious and persistent forms of conduct problems (see Loeber, 1991, for a review). It appears that low verbal IQ and academic underachievement are also precursors to or characteristics of the development of conduct problems (see Hinshaw, 1992, for a review).

Those same child characteristics often affect families' participation in traditional outpatient mental health treatment. Although the length of children's symptom duration has been positively associated with the likelihood that families would continue with therapy (McAdoo \& Roeske, 1973), higher rates of antisocial and delinquent behavior, a greater number of contacts with deviant peers, more comorbid diagnoses, and lower intellectual ability all increase the chances that families terminate treatment prematurely (Kazdin et al., 1993).

\section{Neighborhood Quality}

It appears that living in poor and disorganized neighborhoods increases children's risk for conduct problems and criminal behavior (Sampson \& Groves, 1989). Those increases may exist even after controlling for family, adult, and child characteristics (see Leventhal \& BrooksGunn, 2000, for a review). Being a victim of crime is related to conduct problems (Tiet et al., 2001). In fact, such trauma is specifically related to oppositional defiant disorder, but not attention deficit/hyperactivity disorder or adjustment disorder (Ford et al., 1999).

It seems likely that neighborhood quality could affect parents' and children's participation in treatment as well. Where mental health treatment centers are accessible to all residents, neighborhood quality still predicts adults' mental health service use above and beyond individual characteristics (Driessen, Gunther, \& Van Os, 1998). Although the link between neighborhood quality and children's and families' participation in treatment is less clear, there are community differences in the provision and receipt of children's mental health services (Leaf et al., 1996; Pumariega, Glover, Holzer, \& Nguyen, 1998). Children and families in the poorest communities tend to receive the fewest mental health services (Leaf et al., 1996). 


\section{The Present Study}

Recognizing that many families with young children at high risk for conduct problems fail to engage or participate fully in traditional mental health treatment, there is a need for the design and evaluation of innovative approaches to service delivery. One option is to implement indicated prevention programs that target children's problems early, before they become more serious and contribute to the deterioration of adult psychological functioning and parenting practices (Kazdin, 1990). To ensure that such programs accommodate the needs of children and parents, it also may be necessary to bring mental health services directly to families (Wasik, Bryant, \& Lyons, 1990). There is recent evidence that such innovative approaches in universal and selective prevention programs are successful in recruiting families of young children and adolescents to participate in intervention services (Dumka, Garza, Roosa, \& Stoerzinger, 1997; Gross, Julion, \& Fogg, 2001; Perrino, Coatsworth, Briones, Pantin, \& Szapocznik, 2001; Santisteban et al., 1996; Spoth, Redmond, \& Shin, 2000). There is limited empirical evidence, however, regarding the success of indicated prevention programs in fostering participation among families with young children who already are displaying clinical or subclinical levels of behavior problems but who have not been diagnosed with a psychiatric disorder or sought treatment on their own.

The present study sought to help fill that gap. The indicated prevention program Fast Track (Conduct Problems Prevention Research Group [CPPRG], 1992) was designed to reduce the risk factors for and deflect the developmental trajectories of serious and persistent conduct problems. It was understood that social selection and social influence could operate in ways that made it difficult for those children and families who were most likely to experience negative outcomes to take advantage of what Fast Track provided. To thwart that possibility, Fast Track adopted three separate but related service delivery strategies.

First, in an attempt to be as accessible as possible, Fast Track delivered some of its services in the children's schools. This component of intervention occurred during the day so that participation depended only on initial parent consent and children's presence in class. There is some evidence that providing services in schools rather than clinics improves the chances that poor and minority children will be treated, increases the number of sessions and overall length of treatment, and is as effective as traditional outpatient care in terms of therapist-rated improvement (Armbruster \& Lichtman, 1999).

Second, Fast Track offered therapeutic groups to children and parents in those same schools during the late afternoons, early evenings, or on weekends, so that children and families would be familiar with the setting and attendance would be convenient. In subsequent but similar prevention programs, this has been considered important by over $90 \%$ of families surveyed (Gross et al., 2001). Transportation to and from groups, care for siblings, snacks, and token payments ( $\$ 15$ per family per session) were all provided to reduce potential obstacles to-and enhance motivation for-attendance even further.

Third, Fast Track delivered some of its services as individual home visits. One purpose of these home visits was to reach those families in greatest need who otherwise might not access services (Wasik et al., 1990). We also hoped that these home visits would allow Fast Track clinical staff members to address individual concerns, to promote generalization of new skills to the home environment, and to build closer therapeutic relationships with family members than might be possible in a group context.

A previous study from Fast Track (e.g., Orrell-Valente, Pinderhughes, Valente, Laird, \& CPPRG, 1999) focused on engagement and participation in one component of the intervention. It was found that clinical staff members' own background characteristics—specifically, the similarity between those characteristics and the present circumstances of the families with 
whom they worked - was positively related to the therapeutic bond that developed. It also found that that therapeutic bond was related to the rate and quality of parents' participation in therapeutic groups.

The present study, however, focuses on a broader question: Can the link between risk factors for conduct problems and the receipt of intervention services be broken by offering a community based indicated prevention program and utilizing multiple forms of service delivery? This study hypothesized that systematic efforts to avoid a onesize-fits-all approach to intervention would result in high rates of participation for most children and families in at least some components of the program, especially those components like school-based services and home visits that required less initiative on the parts of children and families. It also hypothesized that the relative advantages and disadvantages of each method of providing intervention services might complement one another and result in different sets of predictors being related to participation across the different components of the program. We expected that the receipt of school-based services would not be related to family or child characteristics; these would depend only on the conscientiousness of Fast Track clinical staff members. We expected that attendance at therapeutic groups would be inversely related to the risk factors for children's conduct problems. We hoped, however, that attendance at these therapeutic groups would only be weakly associated with those risk factors, due to the special efforts Fast Track took to facilitate attendance. Finally, we expected that the receipt of home visits would be positively related to the risk factors for conduct problems; the very purpose of this component of the program was to reach those families in greatest need who would not have received services otherwise.

\section{METHOD}

This study relied on data from the children and families in all three cohorts of the intervention group of Fast Track. It focused on participation in the first year of the program, when all children and families were offered the same amount of prevention services.

\section{Child Screening}

Children and their families were asked to be a part of Fast Track based on a two-stage screening process (see Lochman \& CPPRG, 1995, for more details). Fifty-five schools that served highcrime or low-income neighborhoods were identified in four communities across the United States. It was assumed that these schools were most likely to have children at the highest risk for developing conduct problems.

For three successive years, teachers completed a short questionnaire that assessed oppositional and aggressive behavior problems for every child attending kindergarten. The families of the $40 \%$ of children receiving the highest t-scores (mean 50, SD $=10$ ) on that questionnaire were then contacted to complete a similar questionnaire regarding behavior problems at home. Tscores on the two questionnaires were added together, and the families of the 10-15\% of children at each site receiving the highest scores on that summary screening measure were asked to participate in a longitudinal study of child development. These families were not told, however, that Fast Track also would be offering prevention services if children matriculated at a randomly assigned intervention school. About $92 \%$ of eligible families completed the firstyear study of child development and became part of our intent-to-treat sample; 443 of these 445 families then accepted our offer to provide prevention services.

\section{Study Participants}

About $72 \%$ of the children in this study were boys, and $28 \%$ were girls. At the beginning of this study, all of the children were going into first grade, and most had turned 6 years old. Their 
average $\mathrm{t}$-scores on the externalizing scales of the Teacher Report Form (Achenbach, 1991b) and the parent-reported Child Behavior Checklist (Achenbach, 1991a) were 66.31 and 61.34, respectively. These scores, which are in the clinical or borderline clinical range, are comparable to those of children in a nationally representative sample who received traditional mental health services.

The children and their families lived in some of the most disadvantaged areas of Durham, NC, a small city with a predominantly African American population; Nashville, TN, a mid-size city with mostly European American and African American residents; central Pennsylvania, a rural area with a few small towns and an almost exclusively European American population; or Seattle, WA, a large city with an ethnically-diverse population. About the same number of families lived at each site. About 53\% of our families were African American; $45 \%$ were European American; and 2\% were Asian American, Latino American, or American Indian. Almost all of the families were in the lowest or second lowest category of SES (Hollingshead, 1975). Approximately, $24 \%$ of families did not include a parent who had graduated from high school, and approximately $25 \%$ of families did not include a parent who was working. About $49 \%$ of the families included a single mother only.

\section{The Intervention Program and Dependent Measures}

All aspects of the Fast Track intervention, including screening and recruitment protocols and every session of all components of the curriculum, were described in detail in written manuals. At the beginning of Fast Track, all clinical staff members from all four sites came together for intensive training in those parts of the program they would deliver. Throughout the intervention, clinical staff members received high levels of individual and group supervision. In addition, supervisors at the four study sites participated in weekly, biweekly, or monthly conference calls to ensure implementation fidelity.

The Fast Track intervention program was multilayered. To change the social climate for our high-risk children, Fast Track provided an updated version of Promoting Alternative Thinking Strategies (PATHS; Kusche \& Greenberg, 1994) to all children in the intervention schools. Fast Track sought to augment the impact of PATHS by getting administrators to implement curriculum concepts school-wide. Fast Track also offered individual and group consultation to teachers regarding positive behavior management strategies.

In addition to those universal components of the prevention program, the identified high-risk children and families in Fast Track also received five targeted interventions (see CPPRG, 2002 , for more details). These five interventions fell into the broad categories of school-based services, therapeutic groups, and home visits.

School-Based Services-The school-based services component of the intervention consisted of reading tutoring and peer pairing. Intervention programs that promote academic competence have been shown to improve children's behavior (Coie \& Krehbiel, 1984). For that reason, Fast Track provided phonics-based individual tutoring — adapted from the program developed by Wallach and Wallach (1976) - to each intervention child three times a week. To promote positive interactions with others and to reduce the likelihood that Fast Track children would be rejected by their peers, each intervention child also participated in a 30-min guided play session with a different same-sex classmate each week.

Participation in reading tutoring and peer pairing was recorded by the Fast Track educational coordinators on a weekly basis. The data were combined across the entire year and divided by the intended number of sessions to create an attendance percentage score for reading tutoring and an attendance percentage score of peer pairing. These two attendance percentage scores 
$(r=.75, p<.001)$ were then averaged together to derive an overall attendance percentage score for school-based services.

Therapeutic Groups-Therapeutic groups were offered to both intervention children and their parents. Children's friendship groups were based on previously tested coaching and socialemotional skills programs (e.g., Bierman, Miller, \& Staub, 1987; Coie \& Koeppl, 1990;

Lochman, Burch, Curry, \& Lampron, 1984). They consisted of weekly out-of-school sessions in which an educational coordinator and an assistant guided a group of about five children in appropriate play behavior. They also provided additional training in the social skills children were learning in PATHS. Parent groups occurred at the same time as friendship groups and were led by a family coordinator and an assistant. These groups-which were adapted from the programs developed by Forehand and McMahon (1981) and Webster-Stratton (1989) focused on helping parents enhance their children's success in school. Teachers sometimes joined parent groups to talk about what children were learning in class and to give suggestions about how parents could reinforce the lessons at home. An equally important focus of the parent groups was positive alternatives to harsh or physical punishment. Special efforts were made to ensure that the content of and climate in all parent groups was sensitive to cultural differences among families.

Participation in friendship groups and parent groups was recorded by the Fast Track educational coordinators and family coordinators, respectively, on a weekly basis. Similar to the approach for school-based services, the data were combined across the entire year and divided by the intended number of sessions to create an attendance percentage score for friendship group and an attendance percentage score for parent groups $(r=.79, p<.001)$, which were averaged together.

Home Visits-The final component of Fast Track during the first year of intervention was home visits. Every other week - or more frequently in cases of pressing need-family coordinators scheduled home visits so they could talk with parents about any issues, including personal and financial ones, that might interfere with parents' ability to support their children's positive development. Family coordinators adopted a problem-solving approach to these home visits and attempted to help parents become better advocates for their children and themselves. An important goal of the home visits was to help parents apply the lessons of the weekly therapeutic groups to their individual family situations. When families did not attend those groups, family coordinators often made a home visit within a day or two to review missed material.

Participation in home visits was recorded by the Fast Track family coordinators. Again, data were combined across the entire year and divided by the intended number of sessions to create an attendance percentage score.

\section{Data Collection Procedure and Independent Measures}

Most of the independent variables for this study were collected during home interviews in the summer before children entered first grade. Research staff members received extensive training, including watching videotapes of interviews, observing live interviews, practicing interviews with supervisors, and conducting pilot interviews while being observed. They were expected to achieve minimum criteria for reliability of ratings before conducting any independent home interviews. For behavior observations, such as the parent-child interaction task, additional formal reliability checks were conducted throughout each summer.

During the home interviews, one research staff member met with the parent, and another research staff member met with the child in a separate room. Research staff members read all 
questionnaire items to all parents to sidestep any problems related to literacy. Parents received $\$ 75$ for their time, and children received an assortment of small toys and prizes.

The 11 independent measures in this study were grouped in 5 conceptual categories: family demographics, adult functioning, parenting practices, child characteristics, and neighborhood quality. All measures were coded so that higher scores represented more of the construct (e.g., higher scores on depression represented an endorsement of more symptoms of the disorder, and higher scores on parental warmth represented more sensitive and positive interactions with the child.) Descriptive statistics of all the independent variables are presented in Table I.

Four variables were used to assess family demographics. The first of these was family SES, which was based on a weighting of parents' educational achievement and occupational prestige (Hollingshead, 1975). The second family demographic characteristic was race. It was coded as 1 for African American families and 0 for all other families. The third family demographic characteristic was a dichotomous variable representing whether the parent was single and without a long-term partner living in the home. The final family demographic characteristic indicated the mother's age when her Fast Track child was born.

Two variables were used to measure adult functioning. Depression was assessed with the Center for Epidemiological Studies Depression Scale (Radloff, 1977). In this questionnaire, parents used 4 response options $(0=$ rarely to $3=$ almost all the time) to rate the frequency of 20 symptoms of depression during the past week $(\alpha=.88)$. Stressful life events were tallied after parents indicated whether each of 16 different events, such as death of an important person, serious illness, and financial problems, had occurred during the previous year.

Two variables were used to measure parenting practices. Warmth was assessed with the Interaction Rating Scales (Crnic \& Greenberg, 1990). While parents and children engaged in about $20 \mathrm{~min}$. of free play and semi-structured tasks, the child interviewer made six ratings of parent's enjoyment, responsiveness, and level of involvement $(\alpha=.87)$. Harsh discipline was based on the parent interviewer's rating of a mother's use of physical or punitive punishment. After asking an extended series of questions about how mothers attempted to address common behavior problems, the parent interviewer made a global rating on a 5-point Likert scale ( $1=$ non-restrictive, mostly positive to $5=$ severe, strict, and often physical).

Two variables also were used to assess child characteristics. Children's scores on the summary teacher and parent screening measure were used to represent oppositional and aggressive behavior problems. For the screening measure, teachers completed the Authority Acceptance scale of the Teacher Observation of Classroom Adaptation-Revised (Werthamer-Larsson, Kellam, \& Wheeler, 1991), which had six response options $(0=$ almost never to $5=$ almost always) for 10 items, such as stubborn and fights $(\alpha=.90)$. Parents completed a similar scale, based on items from the Child Behavior Checklist (Achenbach, 1991a) and the Revised Behavior Problem Checklist (Quay \& Peterson, 1987), which had 4 response options ( $1=$ never to $4=$ often) for 24 items, such as sneaky and yells at others $(\alpha=.79)$. The second child characteristic was intellectual ability, as assessed with the Block Design and Vocabulary subtests of the Wechsler Intelligence Scale for Children-Revised (Wecshler, 1974). Agenormed standard scores (mean $=10, S D=3$ ) for each subtest were computed and averaged together for a total score.

Neighborhood quality consisted of indicators of concentrated poverty and physical danger or crime. Data on poverty came from the United States Census Bureau and represented the percentage of families in the Census tract whose income placed them below federal poverty guidelines. Physical danger or crime was based on 4 ratings by the parent interviewer using a 4-point Likert scale. A typical item was "How safe is the area outside of this dwelling?" $(\alpha=$. 73). These scores were standardized and averaged for a total neighborhood quality score. 


\section{RESULTS}

Participation in Fast Track was high for all components of the intervention, irrespective of the context in which services were delivered. Children received an average of 50 of the 60 planned reading tutoring sessions $(S D=13.44)$ and 18 of the 22 planned peer pairing sessions $(S D=$ $5.24)$ for a total of $83 \%$ of all planned school-based services $(S D=.22)$. Children and parents attended about 16 of the 22 planned friendship groups $(S D=5.50)$ and 15 of the 22 planned parent groups ( $S D=6.48$ ), respectively, for a total of $71 \%$ of all therapeutic groups $(S D=$. 26). Families received an average of 12 home visits $(S D=8.64)$ - even though Fast Track initially planned for only 11 - for a total of $112 \%$ of this component of the intervention ( $S D$ $=.79$ ).

\section{Predictors of Participation in Each Component of the Intervention}

In the first stage of data analyses, regression equations were estimated to determine whether our 11 independent variables were related to participation in each component of Fast Track. The results of these analyses are presented in Table II. In all of these regression equationsand the other analyses in this study — standard errors were adjusted using the clustering option in Stata (StataCorp., 1999). This corrects for the fact that children and families were not fully independent, but rather participated in Fast Track in 86 different groups. The 3 to 7 children and families in each group entered Fast Track the same year, attended the same elementary school (or, in a few cases, one nearby), had the same educational coordinator responsible for school-based services, were members of the same friendship group and parent group, and had the same family coordinator making home visits. Each of our independent variables was tested by itself to calculate its total relation to participation. These estimates are the same as bivariate or zero-order correlations, but with adjusted standard errors. In addition, all independent variables were tested jointly to calculate unique relations to participation. These estimates are the standardized partial regression coefficients or betas and represent the relation between that part of the independent variable that does not overlap with any other independent variable and that part of the outcome that has not been accounted for by any other independent variable. In these analyses, variables representing cohort and site were effects coded, so that the projectwide average, rather than the value for an arbitrary cohort or site, served as the reference point. Interactions between the site variables and each independent variable were examined, but retained in the tests of unique relations only when statistically significant as a group.

School-Based Services-When each independent variable was examined by itself, indicators of site were the only significant predictors of the receipt of school-based services. Children who attended elementary schools in the small, stable school districts of rural Pennsylvania were more likely to receive high levels of school-based services whereas children who attended elementary schools in the large, highly mobile school district of Seattle were less likely to receive high levels of school-based services.

Examined together, the entire set of independent variables was related to the receipt of schoolbased services $(F[22,85]=4.19, p<.001)$ and accounted for approximately $13 \%$ of the variance in participation. This analysis indicated that attending school in Pennsylvania $(p<.10)$ or Seattle remained uniquely related to the receipt of school-based services. This analysis also revealed, however, that attending school in Nashville $(p<.10)$, the interaction of site and harsh discipline, having a low IQ $(p<.10)$, and the interaction of site and IQ were uniquely related to the receipt of school-based services. Children in Nashville who experienced more harsh discipline at home were less likely to receive school-based services $(\beta=-.14, p<.05)$, whereas children in Seattle who experienced more harsh discipline at home were more likely to receive school-based services $(\beta=.16, p<.10)$. In addition, the predicted impact of low IQ on the receipt of school-based services $(\beta=-.09, p<.10)$ was cancelled out when children were in 
one of the Pennsylvania school districts $(\beta=.09, p<.05)$, but almost tripled when children were part of the Seattle school district $(\beta=-.17, p<.05)$. Most likely, these site interactions reflect idiosyncratic covariation between the kinds of children and families schools served and dynamics at those schools that impeded or facilitated service delivery by Fast Track educational coordinators. The fact that several independent variables with nonsignificant total effects had significant unique effects suggests that these relations initially were suppressed by other independent variables or that these relations were so specific they initially were overwhelmed by variance the other independent variables later accounted for.

Therapeutic Groups-Tests of total relations indicated that, if children and families were part of Fast Track in Pennsylvania, included a relatively older parent, or experienced a relatively high number of stressful life events $(p<.10)$, they were more likely to attend therapeutic groups. If children and families were part of Fast Track in Durham $(p<.10)$ or were African American, however, they were less likely to attend therapeutic groups.

When examined together, the entire set of independent variables predicted attendance at therapeutic groups $(F[25,85]=4.89, p<.001)$ and accounted for approximately $12 \%$ of the variance. This regression equation showed that being in Pennsylvania, having a relatively older parent, and experiencing more stressful life events $(p<.10)$ had unique as well as total effects on attendance at therapeutic groups. It also showed that participating in Fast Track in Durham or being African American had no unique effects on attendance; these variables were probably redundant with the indicator for rural Pennsylvania where, in contrast to Durham, almost all of the families are European American. This analysis revealed that being in Cohort I, displaying warm interactions, and having a low IQ were uniquely related to attending more therapeutic groups. Using harsh discipline also was $(p<.10)$, but a site interaction indicated this was not true of families in Nashville $(\beta=-.17, p<.001)$. Being part of Fast Track in Seattle was uniquely related to attending fewer therapeutic groups, and living in a poor and dangerous neighborhood in Seattle made this especially likely $(\beta=-.16, p<.05)$.

Home Visits-Tests of total relations indicated that site did not affect the receipt of home visits. Children and families were more likely to receive a high number of home visits when they were relatively low SES, were African American, included a single parent, included a mother with more symptoms of depression, were characterized by fewer warm parent-child interactions and more harsh discipline, included a child with a relatively low IQ, or lived in an especially poor and dangerous neighborhood.

When examined together, the entire set of independent variables predicted the receipt of home visits $(F[16,85]=6.86, p<.001)$ and accounted for approximately $16 \%$ of the variance. Low SES, harsh discipline $(p<.10)$, and low child IQ continued to be uniquely related to the receipt of home visits. Having a relatively older parent also emerged as a unique predictor $(p<.10)$ of the receipt of home visits.

\section{Profiles of Participation Across Components of the Intervention}

In contrast to the previous stage of data analysis, which considered predictors of participation in each component of Fast Track separately, the next stage of data analysis examined meaningful profiles of participation across the different components of the prevention program. Using the latent profile analysis capabilities of Mplus (Muthén \& Muthén, 1998), four distinct and meaningful profiles of participation were identified. ${ }^{6}$ One profile of participation characterized a group of children and families who received almost all of the intervention services as planned; a second profile of participation characterized a group of children and families who participated in fewer school-based services and therapeutic groups but received more home visits than planned; the third profile of participation characterized a group of 
children and families who participated at low levels in all components of the intervention; and the fourth profile of participation characterized a group of children and families who received almost all of the school-based services and therapeutic groups and an exceptionally high number of home visits. The probabilities that children and families assigned to one of the four groups were actually in that group tended to be fairly high with an average of $87 \%$ and a range from $83 \%$ to $90 \%$; the probabilities that children and families assigned to one group were actually members of another group tended to be fairly low with an average of $5 \%$ and a range from $0 \%$ to $11 \%$.

To determine which independent variables predicted membership in each group, multinomial logistic regression equations were estimated. These multinomial logistic regressions followed the same analytic strategy as the linear regressions presented above. The variables representing cohort and site were related to the profile of participation children and families displayed $\left(\chi^{2}\right.$ $=11.56, d f=6, p<.10$, pseudo $R^{2}=.01$, and $\chi^{2}=46.77, d f=9, p<.001$, pseudo $R^{2}=.04$, respectively). When tested individually, family SES, race, marital status, maternal warmth, child IQ, and neighborhood quality also were related to the profile of participation children and families displayed $\left(\chi^{2}\right.$ s ranged from 8.92 to $33.18, d f=3, p<.05, .01$, or .001 , pseudo $R^{2}$ ranged between .01 and .03 ). However, maternal age, maternal depression, stressful life events, harsh discipline, and children's behavior problems were not related to the profile of participation children and families displayed ( $\chi^{2}$ ranged from 3.90 to 5.41, $d f=3, p=\mathrm{ns}$ ). When all independent variables were tested together to examine unique effects, the entire group of independent variables - and significant interactions - was related to the profile of participation children and families displayed $\left(\chi^{2}=2306.84, d f=75, p<.001\right.$, pseudo $\left.R^{2}=.18\right)$.

The results of these multinomial logistic regression analyses are presented in Table III. To summarize the impact of each independent variable on the predicted probability of group membership in each profile of participation, we present marginal effects (Greene, 2000). A transformation of the logistic regression coefficient, marginal effects are easier to interpret than those coefficients and odds ratios. Marginal effects represent the impact of a one-unit increment - such as one extra year in mothers' age, one additional stressful event, or a one standard deviation change from the sample mean in children's behavior problems - on the likelihood of displaying a particular profile of participation. Because marginal effects reflect the relations among the four profiles of participation considered jointly, they eliminate the need to compare all possible pairs of profiles of participation. Because all children and their families are represented in only one profile of participation, the marginal effects for each predictor across profiles sum to 0 .

Group 1-The largest group of children and families in Fast Track had a profile of participation characterized by the receipt of virtually all of the intervention services we hoped to deliver. This group, which comprised $49 \%$ of the sample, received an average of $92 \%$ of school-based services, $88 \%$ of therapeutic groups, and $92 \%$ of home visits. Compared to the average across all four sites, children and families in Durham were 11 percentage points less likely to be in this group, and children and families in Pennsylvania were 22 percentage points more likely to be in this group. In other words, the predicted probability of displaying this profile of participation decreased from 49 to $38 \%$ for children and families in Durham and increased from 49 to $71 \%$ for children and families in Pennsylvania. With each standard deviation increase above the sample mean in SES, children and families were 5 percentage

\footnotetext{
${ }^{6}$ Several different approaches were investigated to identify meaningful profiles of participation, including rule-based criteria (i.e., receiving more or less than $75 \%$ of the planned amount of intervention in each component of Fast Track), traditional cluster analysis, and latent profile analysis. None of these approaches identified more than four groups of children and families that each included at least $5 \%$ of the entire sample (i.e., 22 children and families). Groups smaller than that seemed rare enough to be of limited scientific value. In general, the characteristics of the children and families in these four larger groups appeared similar, even though the different classification methods assigned a few specific children and families to different groups.
} 
points more likely to display this profile of participation. African American children and families were 22 percentage points less likely to be in this group, and single-parent households were 15 percentage points less likely to be in this group. When mothers displayed more warmth toward their children, families were more likely to be in this group, and when children and families lived in Fast Track's relatively less poor and less dangerous neighborhoods, they were more likely to be in this group.

When the effects of all independent variables were examined together, being part of Fast Track in Pennsylvania and warm parent-child interactions uniquely predicted membership in this group. Site interactions revealed that, in Nashville, when children exhibited more behavior problems, they and their families were less likely to be in this group (marginal effect [ME] = $-.08, p<.10)$, but in Seattle, these children and their families were more likely to be in this group $(\mathrm{ME}=.10, p<.10)$.

Group 2-The second largest group of children and families, comprising 35\% of the entire sample, received $78 \%$ of planned school-based services, $60 \%$ of therapeutic groups, and $134 \%$ of planned home visits. Compared to the average across all four sites, children and families in Durham and Nashville were each 9 percentage points more likely to be in this group, and children and families in Pennsylvania were 19 percentage points less likely to be in this group. When children and families were one standard deviation below the sample mean in SES, they were 6 percentage points more likely to be in this group, and African American children and families were 22 percentage points more likely to display this profile of participation. This profile of participation also was more characteristic of families that included a single parent only, families characterized by less warm parent-child interactions, and families who lived in our most dangerous and poor neighborhoods.

When the effects of all independent variables were examined together to identify unique predictors, participating in Fast Track in rural Pennsylvania made it less likely that children and families would be in this group whereas being lower SES $(p<.10)$, being African American $(p<.10)$, and displaying less warm parent-child interactions made it more likely. In addition, a site interaction indicated that, in Seattle only, when children exhibited more behavior problems, they and their families were less likely to be in this group $(\mathrm{ME}=-.14, p<.01)$.

Group 3-Representing about $10 \%$ of the entire sample, the third largest group of children and families in Fast Track had a profile of participation characterized by the receipt of low levels of all components of the intervention. On average, they received just $46 \%$ of schoolbased services, $16 \%$ of therapeutic groups, and $44 \%$ of home visits. Interestingly, these children and families tended to be relatively well-off in terms of SES, and they tended to live in less poor and dangerous neighborhoods.

When the effects of all independent variables were examined together to assess unique effects, children and families in Durham were more likely to display this profile of participation $(p<$. 10 ) whereas children and families in Pennsylvania were less likely to $(p<.10)$. Having a higher SES continued to be related to membership in this group $(p<.10)$, and having a younger mother emerged as a unique predictor. When mothers reported more symptoms of depression, their children and they were more likely to be in this group. Although this did not appear to be true of families in Nashville (ME $=-.04, p<.05$ ), it was especially true of families in Seattle (ME $=.03, p<.10$ ). As families experienced fewer stressful life events, they were more likely to be in this group, and, when families were characterized by fewer warm parent-child interactions, they were more likely to be in this group. In Nashville, when parents used more harsh discipline, their children and they were more likely to be in this group (ME $=04, p<$. $10)$, but in Seattle, they were less likely to be in this group ( $\mathrm{ME}=-.05, p<.05)$. Living in a 
less poor and dangerous neighborhood continued to be uniquely related to displaying this profile of participation.

Group 4-The final group of children and families in Fast Track represented just 6\% of the entire sample. On average they received $96 \%$ of school-based services, $97 \%$ of therapeutic groups, and $266 \%$ of planned home visits. Children and families in Cohort I were less likely to display this profile of participation whereas children and families in Cohort II were more likely to do so $(p<.10)$. When families included a single parent, the predicted probability that they were in this group doubled from 6 to $12 \%$. When children had lower IQs, they and their families also were more likely to be in this group.

When the effects of all independent variables were considered together, cohort was not uniquely related to displaying this profile of participation, but being a single parent and low child IQ were. In addition, when mothers experienced more symptoms of depression, they were less likely to be in this group $(p<.10)$. This was especially true in Nashville $(\mathrm{ME}=-.02, p<$. $05)$; however it was not the case in Seattle $(\mathrm{ME}=.01, p<.10)$. In Nashville only, when parents used more harsh discipline, their children and they were less likely to be in this group ( $\mathrm{ME}=$ $-.01, p<.05)$. In Durham, families that included children with more severe behavior problems were less likely to display this profile of participation $(\mathrm{ME}=-.04, p<.05)$, whereas in Nashville and Seattle, these families were more likely to be in this group $(\mathrm{ME}=.01, p<.10$, and $\mathrm{ME}=$. $02, p<.10$, respectively).

\section{DISCUSSION}

To address the historical incongruity between the need for and receipt of mental health treatment, Fast Track offered an array of prevention services in multiple contexts, including children's schools and families' homes. Most important, this study found that children and families were receptive to such services when offered as part of a comprehensive competencybuilding program. Over $99 \%$ of our intent-to-treat sample (which itself represented $92 \%$ of all eligible high risk children and families) agreed to participate in at least some components of the prevention program.

Despite having the characteristics of a clinical sample-in terms of the severity of children's behavior problems - children and families received an average of 83,71 , and $112 \%$ of planned school-based services, therapeutic groups, and home visits, respectively. Participation across the components of Fast Track was higher than in most other intervention programs for children with conduct problems (Wierzbicki \& Pekarik, 1993; Forehand et al., 1983; Spoth \& Redmond, 2000).

\section{Efforts to Recruit and Retain Children and Families}

Based on our rates of participation, Fast Track's efforts to generate enthusiasm, promote accessibility, and reduce barriers to treatment appear to have been successful. This may have been due to our attempts to develop a culturally-sensitive curriculum that focused on the immediate concerns of parents (Prinz \& Miller, 1991; Prinz et al., 2001). By offering our prevention program at children's entry into school, we might have capitalized on a period in which parents were especially receptive to services. We acknowledged parents' desire to see their children succeed in school, but stressed what a challenge that can be. We emphasized the critical role parents play in children's education, and then offered one easy and concrete step parents could take in fulfilling that role. As a result of the many services we provided to their children, parents may have been more likely to attend therapeutic groups themselves and schedule home visits. Many parents reported being especially enthusiastic about the prospect of their children's receiving individual reading tutoring and stated that was the primary reason they initially were drawn to Fast Track. 
Parents also may have been more likely to attend therapeutic groups because we offered them at convenient times for families and in a familiar, comfortable, and, importantly, non-clinical setting. We did everything we could to avoid having a stigma attached to Fast Track. We provided snacks and token payments as a small incentive to motivate attendance. And, when necessary, we also provided transportation and sibling care.

In addition, children and families may have been more likely to participate in the different components of Fast Track because clinical staff members adopted a "never give-up" attitude toward engagement and retention. If a child and parent did not attend a therapeutic group, their family coordinator was likely to drop by their house to acknowledge their absence, to stress their importance to the group, and to provide support for any problem that might have interfered with attendance. If families were reluctant to participate in therapeutic groups or schedule home visits, family coordinators continued to contact them in an effort to show our commitment to the child and, perhaps, change the parent's mind.

\section{Relations Among Risk Factors for Conduct Problems and Participation in Fast Track}

Children were most likely to receive school-based services. As we had hoped, participation in this component of Fast Track was not consistently affected by most family, parent, child, or neighborhood characteristics. This finding echoes those from previous studies, suggesting that the provision of school-based services is more egalitarian than other forms of service delivery (Lahey et al., 1999; Wu et al., 1999). Surprisingly, many of the factors that typically predict low levels of participation in traditional outpatient mental health treatment, such as family SES, maternal depression, and children's behavior problems, were not related to attendance at Fast Track's therapeutic groups. Similar to the provision of school-based services, home visits were not supposed to depend on the initiative of families, only their receptiveness to intervention services. As a result, Fast Track family coordinators were able to conduct the most home visits with families displaying severe problems. In contrast to other studies in which risk factors for negative outcomes among infants were associated with mothers' refusing home visits (Josten et al., 2002), in Fast Track risk factors for conduct problems, such as low SES and low child IQ, predicted which families would receive more home visits. In fact, many of these families needed — and were provided with—more home visits than Fast Track initially planned to deliver.

This study found that considering school-based services, therapeutic groups, and home visits together provided a clearer understanding of the relations among risk factors for conduct problems and participation in the prevention program. For example, compared to the children and families in Group 1, who received almost all planned intervention services (92, 88, and $92 \%$ of school-based services, therapeutic groups, and home visits, respectively), the children and families in Group 2, who participated in fewer school-based services and therapeutic groups but received more home visits $(78,60$, and $134 \%$, respectively), tended to experience more risk factors for conduct problems. The latter group tended to be lower SES, to include a single parent only, to have mothers who were less warm, and to live in more poor and dangerous neighborhoods. Although children and families in this latter group were less willing or able to participate regularly in the therapeutic groups, they appeared very receptive to individualized home visits that required less organization and effort on their part.

It is noteworthy that a disproportionate number of African American families fell into this latter group. In general, African American children are less likely than European American children to receive mental health services (Zahner \& Daskalakis, 1997). Similar to the findings from other prevention programs (Perrino et al., 2001), our findings suggest that factors aside from availability and access to the therapeutic groups were at play. By supplementing the therapeutic groups with school-based services and individualized home visits, however, Fast Track was able to reach these children and parents who might not have received services otherwise. 
The small number of children and families in Group 3, who participated in less than 50\% of each component of Fast Track, and the small number of children and families in Group 4, who participated in more than $95 \%$ of each component of the intervention, showed an interesting mix of risk factors for conduct problems. The children and families in Group 3 tended to be higher SES, to experience fewer stressful life events, such as the loss of a job, and to live in less poor and dangerous neighborhoods than other children and families in Fast Track. At the same time, the mothers in these families were younger, more depressed, and less warm.

Although, by design, all of the children in Fast Track were at high risk for developing serious conduct problems, parents were not aware of this. Because these families were better off financially than other families in their communities, the parents may not have believed that their children needed help. In contrast, the children and families in Group 4 tended to include single but less depressed mothers and children with more severe behavior problems and lower IQs. Several of these families were confronting exceptional circumstances, such as the presence of a severe and chronic illness, which contributed to the need for so many home visits.

\section{Service Delivery in Four Diverse Communities and School Districts}

Although Fast Track is one prevention program, in some ways it represents four concurrent replications of an innovative service delivery system. By design, Fast Track was implemented in quite different communities with very different kinds of school districts. Although not planned, it is understandable that study site was one of the stronger predictors of participation in the program. Children living in the rural areas of Pennsylvania tended to receive more schoolbased services, and children in Seattle tended to receive fewer school-based services. Anecdotal accounts suggest that scheduling pull-out intervention services for our high risk children was easier in those small rural school districts where there was less turnover among children, teachers, and administrators. Scheduling such services was a greater challenge when children moved to schools that were far away and when relationships with the teachers and administrators in those new schools had to be developed individually and anew. This was often the case in Seattle, where turnover among students and teachers was particularly high.

Children and families in Pennsylvania also were more likely to attend therapeutic groups than were children and families in Durham, Nashville, and Seattle. This might be due to the fact that the less-mobile residents of rural Pennsylvania are more likely to have long-standing relationships with their local elementary schools. Moreover, in rural Pennsylvania, school districts sometimes cross townships and assume prominence in identifying the broadly conceived "community" to which families belong. Therefore, becoming even more involved in activities offered through these schools may have felt quite comfortable for families in Pennsylvania. In contrast, many of our urban schools relied on bussing and were less connected to the neighborhoods of the children and families they served. Because our low-income parents were less likely to drop by these schools on a regular basis, it may have felt less natural and welcoming to attend therapeutic groups at them.

Interestingly, site was least important in predicting how many home visits families received. This was the component of Fast Track least influenced by families' relationships with schools. When Fast Track depended only on its family coordinators to build and maintain positive relationships with children and families, it appeared successful in avoiding site differences.

Although Fast Track made exceptional efforts to ensure cross-site fidelity of program implementation, there were some interactions between site and factors predicting participation. Some of these interactions undoubtedly reflect the striking demographic, social-ecological, and cultural differences that were not accounted for elsewhere in this study. Other interactions, such as the finding that children in Seattle with lower IQs received more school-based services, probably reflect an informal decision by a particular group of educational coordinators to expend extra time and resources on those children who needed more help. The fact that site 
interactions were most common with factors predicting membership in the more extreme profiles of participation (e.g., the $10 \%$ of families who had low rates of participation in all components of Fast Track and the $6 \%$ of families who had especially high rates of participation in all components of Fast Track) most likely reveals the idiosyncratic differences of the few families at each site who happened not to be interested in the program or who happened to need exceptionally high levels of support. In other words, the small number of families in each of these groups at each site may have decreased the predictive validity and reliability of the other factors.

\section{Strengths and Limitations of the Current Study}

In examining participation, this study had several advantages. First, and most important, this is one of the few studies to focus on multiple components of a prevention program offered in different contexts. Second, this study targeted families identified through a population-based screening, rather than families who were self-referred. Third, this study included a much larger sample of families than most previous studies in the area. Fourth, the sample for this study was quite diverse. It included families from four different states and families who lived in urban and rural areas. This study also included families who were almost equally divided according to race. Fifth, this study assessed multiple domains of potential predictors of participation. And, finally, this study utilized multiple measures of these predictors, including parent reports, teacher reports, behavioral observations, and public records.

Despite the strengths of this study, several factors affect the conclusions that can be drawn from it. The most important of these limitations is that Fast Track was not designed to examine predictors of participation. Ideally, all children and their families would have attended all sessions of all components of the prevention program. That is what would have been best for the intervention and control group comparisons that were the primary focus of Fast Track. Given that there was variation in participation, however, this study sought to examine what we could learn from it. As a result of the many program features that were enacted to overcome common barriers to service use, rates of participation in the different components of Fast Track probably were attenuated. Hence, the findings of this study may not apply to all prevention programs, especially those without the resources of a clinical trial. In addition to that restricted range in participation, there also was a restricted range in the high-risk children and families who participated in Fast Track. We know from other studies that skewed study samples can result in an underestimation of the magnitude of family environment effects (Stoolmiller, 1999). It would not be surprising if different and additional factors predict-and predict more strongly - participation in a universal or selective prevention program that includes more children without clinical or sub-clinical behavior problems. Finally, this study adjusted for what it considered to be the most important level of nesting of children and families, but it could not account for all of the different levels of nesting, such as school districts within the Pennsylvania site, that also might have influenced rates of participation.

\section{Conclusions and Implications}

By providing an indicated prevention program in multiple easily-accessible contexts, Fast Track was able to surmount the barriers that factors such as poverty, single parent status, depression, child behavior problems, and dangerous neighborhoods can pose in receiving traditional mental health services. Our findings support current trends in prevention research for providing multiple, coordinated service delivery mechanisms, so that the form and intensity of mental health services can match the preferences and needs of children and families (see reviews by Coie et al., 1993; Hogue \& Liddle, 1999; Santos, Henggeler, Burns, Arana, \& Meisler, 1995). 
Although Fast Track was designed to be a study of efficacy not effectiveness, its lessons may have implications for the way we go about providing and delivering mental health services in general. It appears that our 10-item teacher screening measure was able to accurately identify those non-intervention children who ended up using mental health services, being placed in special education, or becoming involved with the juvenile justice system during elementary school (Jones, Dodge, Foster, Nix, \& CPPRG, 2002). Perhaps, more communities and schools serving high-risk children could use this kind of screening as a means of providing those children and their families with prevention services early, rather than more costly interventions once problems become serious. It also may be worthwhile to offer more mental health services in schools. Some community mental health centers have arranged to house therapists in schools and get reimbursed from their normal funding sources for the services they provide. Such an arrangement ensures that children can get the services they need with the least disruption to their learning. When children and families still do not access those services, however, it might be important to enable the same therapists to make home visits.

Without question, providing comprehensive and intensive prevention programs like Fast Track can be expensive. But leaving children and adolescents untreated or providing them with insufficient or ineffective mental health services for their conduct problems is also expensive (Cohen, 1998). There is evidence that high-quality prevention programs can yield greater returns in reducing crime for each dollar spent than extended incarceration (Greenwood, Model, Rydell, \& Chiesa, 1998). In the long run, high-quality prevention programs often save society more money than they cost (Aos, Lieb, Mayfield, Miller, \& Pennucci, 2004). Many county and state policy makers are beginning to realize this. They have chosen to increase or redirect social service funding to support effective, albeit expensive, prevention programs like the Nurse-Family Partnership (Olds et al., 1998; see also

www.NCCFC.Org/nurseFamilyPartnership.cfm). Given the scant evidence of effectiveness for outpatient mental health services as they typically are delivered in the community (Weisz, Weiss, \& Donenberg, 1992), there is clearly a need to be more strategic, meticulous, and innovative in our attempts to reduce the prevalence of conduct problems.

\section{ACKNOWLEDGMENTS}

Support for this research was provided by the National Institute of Mental Health (NIMH) through grants R18MH48083, R18MH59051, R18MH50952, R18MH50953, K05MH00797, and K05MH01027 to the Conduct Problems Prevention Research Group. The Center for Substance Abuse Prevention also provided support through a memorandum of support with NIMH, and the Department of Education provided support through grant S184430002. The authors wish to thank Nina Martin and Damon Jones for their help with this study. They also wish to thank the children, parents, teachers, and school district personnel who made Fast Track possible.

\section{REFERENCES}

Achenbach, TM. Manual for the child behavior checklist/4-18 and 1991 profile. University of Vermont Department of Psychiatry; Burlington, VT: 1991a.

Achenbach, TM. Manual for the teacher's report form and 1991 profile. University of Vermont Department of Psychiatry; Burlington, VT: 1991b.

Ackerman BP, Brown ED, D'Eramo KS, Izard CE. Maternal relationship instability and the school behavior of children from disadvantaged families. Developmental Psychology 2002;38:694-704. [PubMed: 12220048]

Armbruster P, Lichtman J. Are school based mental health services effective? Evidence from 36 inner city schools. Community Mental Health Journal 1999;35:493-504. [PubMed: 10863986]

Armbruster P, Schwab-Stone ME. Sociodemographic characteristics of dropouts from a child guidance clinic. Hospital and Community Psychiatry 1994;45:804-808. [PubMed: 7982697] 
Aos, S.; Lieb, R.; Mayfield, J.; Miller, M.; Pennucci, A. Benefits and costs of prevention and early intervention programs for youth. Washington State Institute for Public Policy; 110 5th Avenue SE, Suite 214, Olympia WA 98504: 2004. Available fromwww.WSIPP.WA.Gov.

Bierman KL, Miller CM, Staub S. Improving the social behavior and peer acceptance of rejected boys: Effects of social skill training with instructions and prohibitions. Journal of Consulting and Clinical Psychology 1987;55:194-200. [PubMed: 3571672]

Clark DB, Baker BL. Predicting outcome in parent training. Journal of Consulting and Clinical Psychology 1983;51:309-311. [PubMed: 6841775]

Cohen MA. The monetary value of saving a high-risk youth. Journal of Quantitative Criminology 1998;14:5-33.

Coie JD, Krehbiel G. Effects of academic tutoring on the social status of low-achieving, socially rejected children. Child Development 1984;55:1465-1478.

Coie, JD.; Koeppl, GK. Adapting intervention to the problems of aggressive and disruptive rejected children. In: Asher, SR.; Coie, JD., editors. Peer rejection in childhood. Cambridge University Press; New York: 1990. p. 309-337.

Coie JD, Watt NF, West SG, Hawkins JD, Asarnow JR, Markman HJ, Ramey SL, Shure MB, Long B. The science of prevention: A conceptual framework and some directions for a national research program. American Psychologist 1993;48:1013-1022. [PubMed: 8256874]

Conduct Problems Prevention Research Group. A developmental and clinical model for the prevention of conduct disorder: The FAST Track Program. Development and Psychopathology 1992;4:509_ 527.

Conduct Problems Prevention Research Group. The implementation of the Fast Track Program: An example of a large-scale prevention science efficacy trial. Journal of Abnormal Child Psychology 2002;30(1):1-17. [PubMed: 11930968]

Crnic KA, Greenberg MT. Minor parenting stresses with young children. Child Development 1990;61:1628-1637. [PubMed: 2245752]

Driessen G, Gunther N, Van Os J. Shared social environment and psychiatric disorder: A multilevel analysis of individual and ecological effects. Social Psychiatry and Psychiatric Epidemiology 1998;33:606-612. [PubMed: 9857793]

Dumka LE, Garza CA, Roosa MW, Stoerzinger HD. Recruitment and retention of high-risk families into a preventive parent training intervention. Journal of Primary Prevention 1997;18:25-39.

Firestone P, Witt JE. Characteristics of families completing and prematurely discontinuing a behavioral parent-training program. Journal of Pediatric Psychology 1982;7:209-222. [PubMed: 7108696]

Ford JD, Racusin R, Daviss WB, Ellis CG, Thomas J, Rogers K, Reiser J, Schiffman J, Sengupia A. Trauma exposure among children with oppositional defiant disorder and attention deficithyperactivity disorder. Journal of Consulting and Clinical Psychology 1999;67:786-789. [PubMed: 10535245]

Forehand, R.; McMahon, RJ. Helping the noncompliant child: A clinician's guide to parent training. Guilford; New York: 1981.

Forehand R, Middlebrook J, Rogers T, Steffe M. Dropping out of parent training. Behaviour Research and Therapy 1983;21:663-668. [PubMed: 6661150]

Greene, WH. Econometric analysis. Vol. 4th ed.. Prentice-Hall; Upper Saddle River, NJ: 2000.

Greenwood, PW.; Model, KE.; Rydell, CP.; Chiesa, JR. Diverting children from a life of crime: Measuring costs and benefits. Rand; Santa Monica, CA: 1998.

Gross D, Julion W, Fogg L. What motivates participation and dropout among low-income urban families of color in a prevention intervention? Family Relations 2001;50:246-254.

Hinshaw SP. Externalizing behavior problems and academic underachievement in childhood and adolescence: Causal relationships and underlying mechanisms. Psychological Bulletin 1992;111:127-155. [PubMed: 1539086]

Hogue A, Liddle HA. Family-based preventive intervention: An approach to preventing substance use and antisocial behavior. American Journal of Orthopsychiatry 1999;69:278-293. [PubMed: 10439843]

Hollingshead, AA. Four-factor index of social status. Yale University; New Haven, CT: 1975. Unpublished manuscript 
Jaffee S, Caspi A, Moffitt TE, Belsky J, Silva P. Why are children born to teen mothers at risk for adverse outcomes in young adulthood? Results from a 20-year longitudinal study. Development and Psychopathology 2001;13:377-397. [PubMed: 11393652]

Jones DE, Dodge KA, Foster EM, Nix R, Conduct Problems Prevention Research Group. Early identification of children at risk for costly mental health service use. Prevention Research 2002;3:247-256.

Josten LE, Savik K, Anderson MR, Benedetto LL, Chabot CR, Gifford MJ, McEiver J, Schorn MA, Frederickson B. Dropping out of maternal and child home visits. Public Health Nursing 2002;19:310. [PubMed: 11841677]

Kazdin AE. Premature termination from treatment among children referred for antisocial behavior. Journal of Child Psychology and Psychiatry 1990;31:415-425. [PubMed: 2318922]

Kazdin AE, Mazurick JL, Bass D. Risk for attrition in treatment of antisocial children and families. Journal of Clinical Child Psychology 1993;22:1-16.

Kusche, CA.; Greenberg, MT. The PATHS curriculum. Developmental Research and Programs; Seattle, WA: 1994.

Lahey BB, Goodman SH, Waldman ID, Bird H, Canino G, Jensen P, Regier D, Leaf PJ, Gordon R, Applegate B. Relation of age of onset to the type and severity of child and adolescent conduct problems. Journal of Abnormal Child Psychology 1999;27:247-260. [PubMed: 10503644]

Lahey BB, Loeber R, Hart EL, Frick PJ, Applegate B, Zhang Q, Green SM, Russo MF. Four-year longitudinal study of conduct disorder in boys: Patterns and predictors of persistence. Journal of Abnormal Psychology 1995;104:83-93. [PubMed: 7897057]

Leaf PJ, Alegria M, Cohen P, Goodman SH, Horwitz SM, Hoven CW, Narrow WE, Vaden-Kiernan M, Regier DA. Mental health service use in the community and schools: Results from the fourcommunity MECA study. Journal of the American Academy of Child and Adolescent Psychiatry 1996;35:889-897. [PubMed: 8768348]

Leventhal T, Brooks-Gunn J. The neighborhoods they live in: The effects of neighborhood residence on child and adolescent outcomes. Psychological Bulletin 2000;126:309-337. [PubMed: 10748645]

Lochman JE, the Conduct Problems Prevention Research Group. Screening of child behavior problems for prevention programs at school entry. Journal of Consulting and Clinical Psychhology 1995;63:549-559.

Lochman JE, Burch PR, Curry JF, Lampron LB. Treatment and generalization effects of cognitivebehavioral and goal-setting interventions with aggressive boys. Journal of Consulting and Clinical Psychology 1984;52:915-916. [PubMed: 6501680]

Loeber R. Antisocial behavior: More enduring than changeable? Journal of the American Academy of Child and Adolescent Psychiatry 1991;30:393-397. [PubMed: 2055875]

Loeber R, Green SM, Keenan K, Lahey BB. Which boys will fare worse? Early predictors of the onset of conduct disorder in a six-year longitudinal study. Journal of the American Academy of Child and Adolescent Psychiatry 1995;34:499-509. [PubMed: 7751264]

Luoma I, Tamminen T, Kaukonen P, Laippala P, Puura K, Salmelin R, Almqvist F. Longitudinal study of maternal depressive symptoms and child well-being. Journal of the American Academy of Child and Adolescent Psychiatry 2001;40:1367-1374. [PubMed: 11765281]

McAdoo WG, Roeske NA. A comparison of defectors and continuers in a child guidance clinic. Journal of Consulting and Clinical Psychology 1973;40:328-334. [PubMed: 4144364]

McDermott PA, Spencer MB. Racial and social class prevalence of psychopathology among school-age youth in the United States. Youth and Society 1997;28:387-414.

McLeod JD, Shanahan MJ. Trajectories of poverty and children's mental health. Journal of Health and Social Behavior 1996;37:207-220. [PubMed: 8898493]

McMahon RJ, Forehand R, Greist DL, Wells KC. Who drops out of treatment during parent behavioral training? Behavioral Counseling Quarterly 1981;1:79-85.

Muthén, LK.; Muthén, BO. Mplus user's guide. Muthén \& Muthén; Los Angeles, CA: 1998.

Myers HF, Taylor S, Alvy KT, Arrington A, Richardson MA. Parental and family predictors of behavior problems in inner-city black children. American Journal of Community Psychology 1992;20:557576. [PubMed: 1485611] 
Nagin D, Tremblay RE. Trajectories of boys' physical aggression, opposition, and hyperactivity on the path to physically violent and nonviolent juvenile delinquency. Child Development 1999;70:11811196. [PubMed: 10546339]

Nagin DS, Tremblay RE. Parental and early childhood predictors of persistent physical aggression in boys from kindergarten to high school. Archives of General Psychiatry 2002;58:389-394. [PubMed: 11296100]

Offord DR, Boyle MH, Szatmari P, Rae-Grant N, Links PS, Cadman DT, Byles JA, Crawford JW, Blum HM, Byrne C, Thomas H, Woodward CA. Ontario child health study, II: Six-month prevalence of disorder and rates of service utilization. Archives of General Psychiatry 1987;44:832-836. [PubMed: 3498458]

Olds D, Henderson CR Jr. Cole R, Eckenrode J, Kitzman H, Luckey D, Pettit L, Sidora K, Morris P, Powers J. Long-term effects of nurse home visitation on children's criminal and antisocial behavior. Journal of the American Medical Association 1998;280:1238-1244. [PubMed: 9786373]

O'Leary SG, Slep AMS, Reid MJ. A longitudinal study of mothers' overreactive discipline and toddlers' externalizing behavior. Journal of Abnormal Child Psychology 1998;27:331-341. [PubMed: 10582835]

Orrell-Valente JK, Pinderhughes EE, Valente E Jr. Laird RD, the Conduct Problems Prevention Research Group. If it's offered, will they come? Influences on parents' participation in a community-based conduct problems prevention program. American Journal of Community Psychology 1999;27:753783. [PubMed: 10723534]

Quay, HC.; Peterson, DR.; Quay, HC. Manual for the revised behavior problem checklist. University of Miami; Box 248074, Coral Galbes FL 33124: 1987. Available from

Perrino T, Coatsworth JD, Briones E, Pantin H, Szapocznik J. Initial engagement in parent-centered preventive interventions: A family systems perspective. The Journal of Primary Prevention 2001;22:21-44.

Prinz RJ, Miller GE. Issues in understanding and treating childhood conduct problems in disadvantaged populations. Journal of Clinical Child Psychology 1991;20:379-385.

Prinz RJ, Smith EP, Dumas JE, Laughlin JE, White DW, Barron R. Recruitment and retention of participatnts in prevention trials involving family-based interventions. American Journal of Preventive Medicine 2001;20:31-37. [PubMed: 11146258]

Pumariega AJ, Glover S, Holzer CE III, Nguyen H. Utilization of mental health services in a tri-ethnic sample of adolescents. Community Mental Health Journal 1998;34:145-156. [PubMed: 9620159]

Radloff L. The CES-D Scale: A self-report depression scale for research in the general population. Journal of Applied Psychological Measurement 1977;1:385-401.

Rinn RC, Vernon JC, Wise MJ. Training parents of behaviorally-disordered children in groups: A three years' program evaluation. Behavior Therapy 1975;6:378-387.

Robins LN. Epidemiological approaches to natural history research: Antisocial disorders in children. Journal of the American Academy of Child Psychiatry 1981;20:566-580. [PubMed: 7310022]

Sampson RJ, Groves WB. Community structure and crime: Testing social-disorganization theory. American Journal of Sociology 1989;94:774-802.

Santisteban DA, Szapocznik J, Perez-Vidal A, Kurtines WM, Murray EJ, LaPerriere A. Efficacy of intervention for engaging youth and families into treatment and some variables that may contribute to differential effectiveness. Journal of Family Psychology 1996;10:35-44.

Santos AB, Henggeler SW, Burns BJ, Arana GW, Meisler N. Research on field-based services: Models for reform in the delivery of mental health care to populations with complex clinical problems. American Journal of Psychiatry 1995;152:1111-1123. [PubMed: 7625457]

Spoth R, Redmond C. Research on family engagement in preventive interventions: Toward improved use of scientific findings in primary prevention practice. Journal of Primary Prevention 2000;21:267284.

Spoth R, Redmond C, Shin C. Modeling factors influencing enrollment in family-focused preventive intervention research. Prevention Science 2000;1:213-225. [PubMed: 11523749]

Stanger C, McConaughy SH, Achenbach TM. Three-year course of behavioral/emotional problems in a national sample of 4- to 16-year-olds: II. Predictors of syndromes. Journal of the American Academy of Child and Adolescent Psychiatry 1992;31:941-950. [PubMed: 1400129] 
StataCorp.. Stata Statistical Software: Release 6.0. Stata Corporation; College Station, TX: 1999.

Stoolmiller M. Implications of the restricted range of family environments for estimates of heritability and nonshared environment in behavior-genetic adoption studies. Psychological Bulletin 1999;125:392-409. [PubMed: 10414224]

Tiet QQ, Bird HR, Hoven CW, Moore R, Wu P, Wicks J, Jensen PS, Goodman S, Cohen P. Relationship between specific adverse life events and psychiatric disorders. Journal of Abnormal Child Psychology 2001;29:153-164. [PubMed: 11321630]

Vissing YM, Straus MA, Gelles RJ, Harrop JW. Verbal aggression by parents and psychosocial problems of children. Child Abuse and Neglect 1991;15:223-238. [PubMed: 2043974]

Wahler RG, Dumas JE. Attentional problems in dysfunctional mother-child interactions: An interbehavioral model. Psychological Bulletin 1989;105:116-130. [PubMed: 2648437]

Wallach, MA.; Wallach, L. Teaching all children to read. University of Chicago Press; Chicago: 1976.

Wasik, BH.; Bryant, DM.; Lyons, CM. Home visiting: Procedures for helping families. Sage; Newbury Park, CA: 1990.

Webster-Stratton, C. The parents and children series. Castalia; Eugene, OR: 1989.

Webster-Stratton C. Stress: A potential disruptor of parent perceptions and family interactions. Journal of Clinical Child Psychology 1990;19:302-312.

Wecshler, D. The Wecshler Intelligence Scale for Children-Revised. Psychological Corporation; New York: 1974.

Weisz JR, Weiss B, Donenberg GR. The lab versus the clinic: Effects of child and adolescent psychotherapy. American Psychologist 1992;47:1578-1585. [PubMed: 1476328]

Werthamer-Larsson L, Kellam SG, Wheeler L. Effect of first grade classroom environment on shy behavior, aggressive behavior, and concentration problems. American Journal of Community Psychology 1991;19:585-602. [PubMed: 1755437]

Wierzbicki M, Pekarik G. A meta-analysis of psychotherapy dropout. Professional Psychology: Research and Practice 1993;24:190-195.

Wu P, Hoven CW, Bird HR, Moore RE, Cohen P, Alegria M, Dulcan MK, Goodman SH, Horwitz SM, Lichtman JH, Narrow WE, Rae DS, Regier DA, Roper MT. Depressive and disruptive disorders and mental health service utilization in children and adolescents. Journal of the American Academy of Child and Adolescent Psychiatry 1999;38:1081-1090. [PubMed: 10504806]

Zahner GEP, Daskalakis C. Factors associated with mental health, general health, and school-based service use for child psychology. American Journal of Public Health 1997;87:1440-1448. [PubMed: 9314794] 
Nix et al.

Page 22

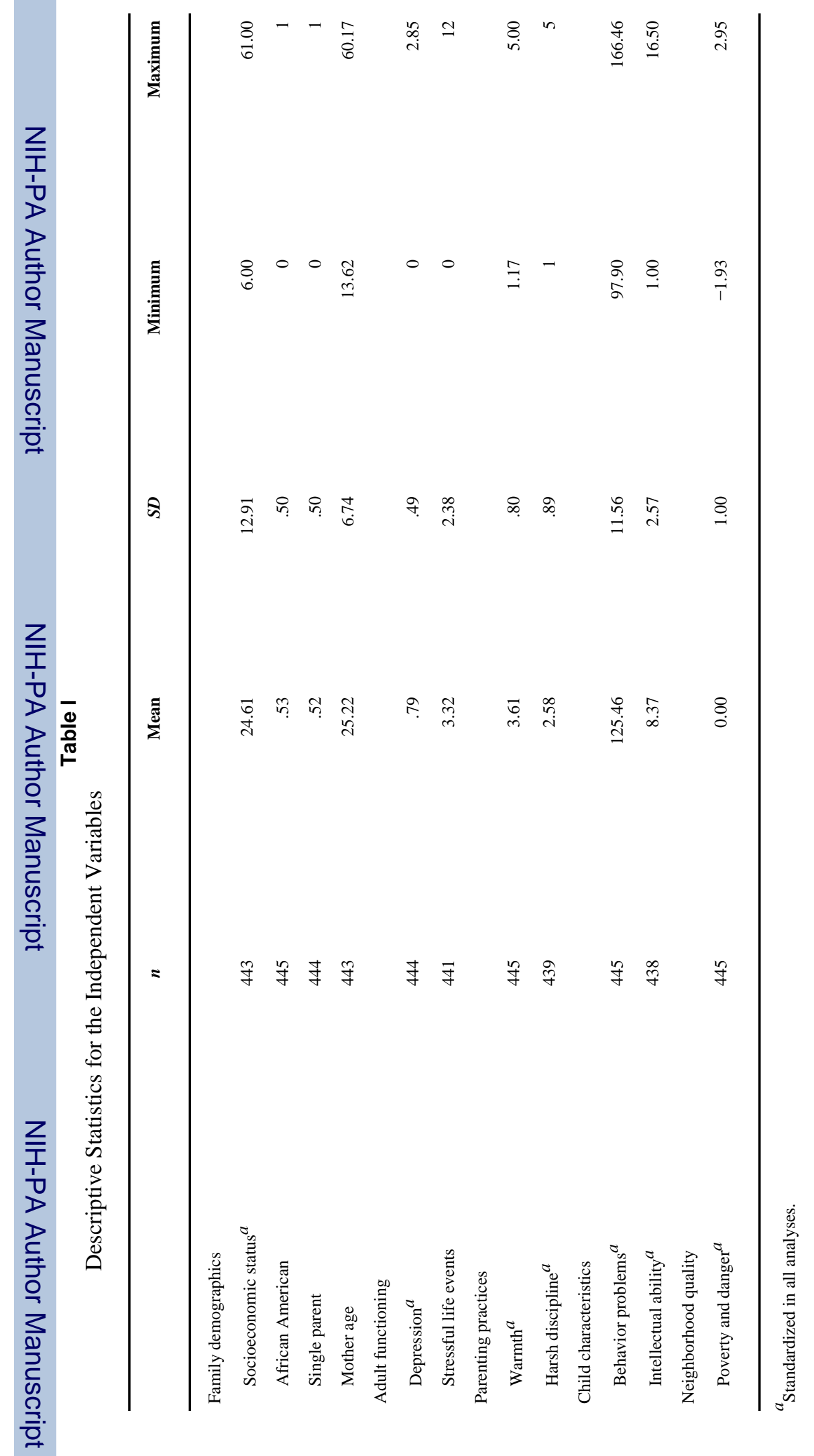

Am J Community Psychol. Author manuscript; available in PMC 2009 September 29. 


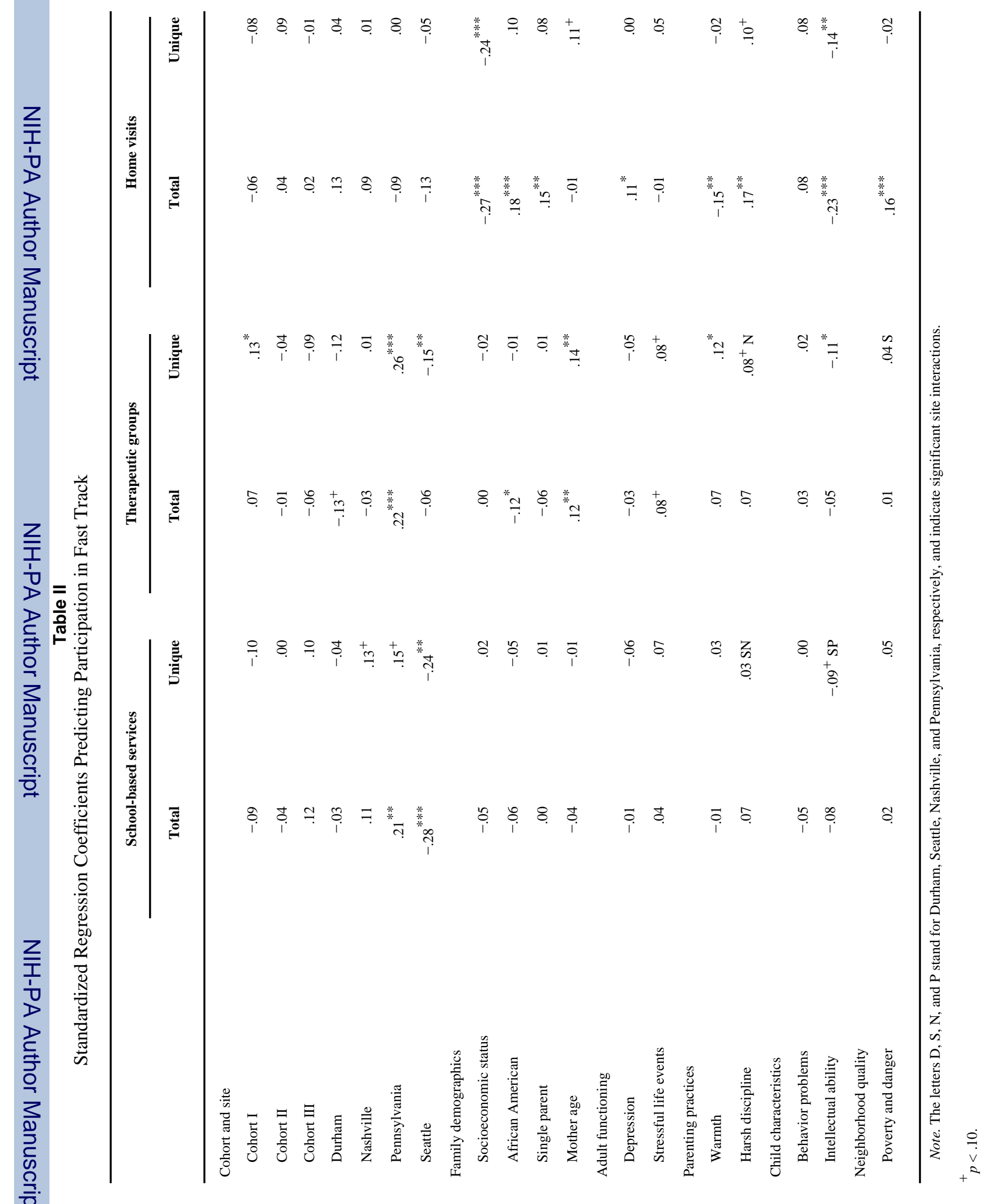
Am J Community Psychol. Author manuscript; available in PMC 2009 September 29. 


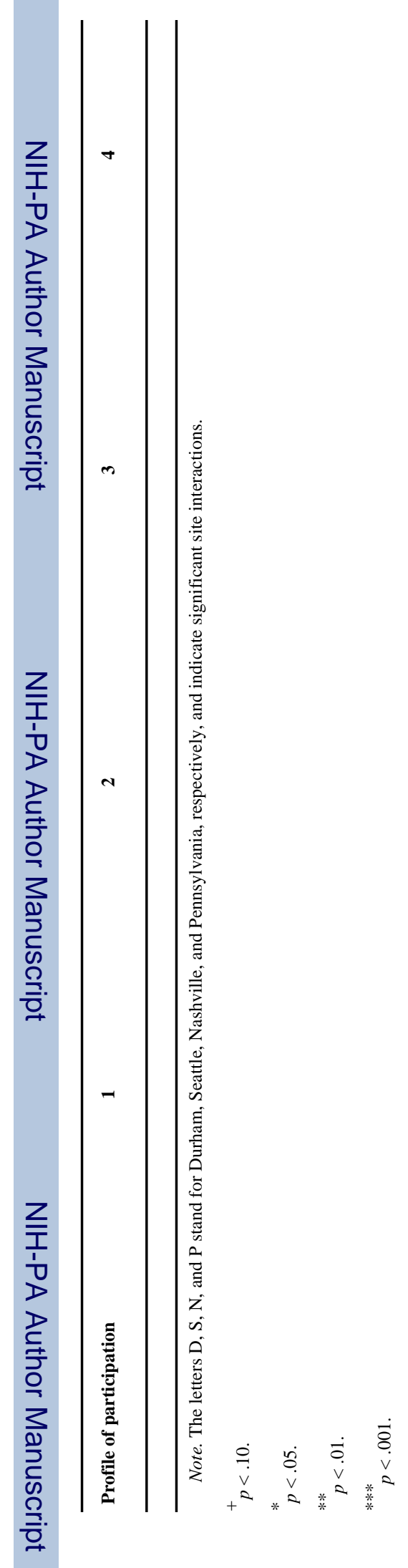

